\title{
A Web-Based Geotechnical GIS
}

\author{
Andrew J. Graettinger, ${ }^{1}$ Zachary T. Ryals, ${ }^{1}$ and Randy K. Smith ${ }^{2}$ \\ ${ }^{1}$ Civil, Construction, and Environmental Engineering Department, The University of Alabama, 260 HM Comer, \\ Tuscaloosa, AL 35487, USA \\ ${ }^{2}$ Computer Science Department, The University of Alabama, 2019-B Shelby, Tuscaloosa, AL 35487, USA
}

Correspondence should be addressed to Andrew J. Graettinger, andrewg@eng.ua.edu

Received 23 June 2011; Accepted 4 August 2011

Academic Editors: J. D. Nelson and I. Smith

Copyright ( $) 2011$ Andrew J. Graettinger et al. This is an open access article distributed under the Creative Commons Attribution License, which permits unrestricted use, distribution, and reproduction in any medium, provided the original work is properly cited.

\begin{abstract}
A web-based Geotechnical Geographic Information System (GeoGIS) was developed and tested for the Alabama Department of Transportation. This web-based system stores geotechnical information about transportation projects, such as subsurface data, construction drawings, and design information. Typically, this information is in a report or plan sheet format, but raw geotechnical data can also be accommodated in the GeoGIS. The goal of this system is to provide easy access and storage for all geotechnical and subsurface structural information from across a state. Access through a secure web interface allows for keyword searches and interactive map selection. The web-based GeoGIS has four geotechnical layers (project, bridge, foundation, and soil boring) that can be displayed on a road map, aerial photos, or USGS 7.5 minute quadrangles. For testing purposes the GeoGIS was populated with multiple document types, formats, and sizes. In all cases, the system performed above expectations.
\end{abstract}

\section{Introduction}

The Alabama Department of Transportation (ALDOT) and other state highway agencies from across the country have amassed significant quantities of information related to geotechnical engineering within their respective states. Geotechnical information includes, but is not limited to, subsurface investigation data, laboratory testing, construction drawings, design information, and performance data [1]. This information is very valuable to future projects, and therefore proper stewardship over the data is an important component of the engineering process. Geotechnical information can come from a number of sources including bureaus from within a department and from a number of outside consultants. The majority of geotechnical information is collected during the early stages of a project, but some information is collected during construction and some during the life of a project for monitoring purposes. This information may be submitted to the central office or to district offices. Historically, this information has been submitted on paper in the form of reports, plans, or test results. Currently, the paper format is being replaced with electronic versions.

Because of the complex nature of project documentation management, maximizing the benefit of past geotechnical data is virtually impossible. It was determined in the state of Alabama that a geotechnical document management system was needed to electronically upload, store, and access geotechnical and subsurface structural data for transportation projects in the state. A geotechnical data management system, based on a Geographic Information System (GIS), was developed to meet ALDOT requirements.

The prototype Geotechnical Geographic Information System (GeoGIS) was developed and tested on a desktop computer. Based on the success of the prototype system, the GeoGIS was migrated from a desktop-based system to a web-based system. The web-based GeoGIS allows authorized users access to geotechnical documents and a GIS map from any computer that has an internet connection. This greatly increased the availability of the GeoGIS by creating a means for field engineers and authorized consultants to access the system.

\section{Background}

Most researchers who have tackled the issue of storing and visually representing geotechnical data have chosen to create a standard method of identifying elemental data. These methods can employ a relational database to store data 
such as blow count at a specific location and depth or can employ a standardized data coding method such as a markup language. A markup language (ML), which is a standard computer science approach of describing individual pieces of data in a way that web browsers can recognize and search engines can index [2-4], has been researched for geotechnical data. GeoML or GeotechML are two proposed geotechnical markup languages.

Markup languages require that every data element be followed by a description, or coding, of what that element describes. This allows for tremendous flexibility but also requires the overhead of entering and storing the data element descriptions. When there is a remarkable number of data elements involved, such as that which is involved in the storage of geotechnical data elements for a large area, the effort of data entry can outweigh the benefit of the graphical representation the markup language offers.

Instead of capturing individual data elements and tagging the elements with markup language flags, the GeoGIS is based on a centralized database that stores geotechnical documents, document data, and associated locations. This differs from what has been reported in the literature because the GeoGIS is designed to meet the specific needs of ALDOT. Rather than creating an online database of geotechnical data elements, this system focuses on project documents related to geotechnical information. The system can also store and retrieve raw or elemental data if projects contain that information. The GeoGIS allows for quick loading, searching, and displaying of geotechnical data.

Some development efforts for web-based geotechnical information systems, such as the GeoInfoSys in Singapore [5], have emphasized the importance of migration from image-based data elements to standardized entry formats. The GeoInfoSys uses a borehole entry form that is extremely detailed and allows fast querying functionality; however, it requires an incredible effort for data entry and is only predefined for borehole data in the system. The GeoGIS system has been designed to allow easy document upload from several approved sources, such as outside geotechnical consultants, as well as providing options for a variety of different types of documents to be uploaded, and is not necessarily limited to geotechnical data, as are many of the similar systems developed in the past.

A small number of web-based geodatabase geotechnical systems exist, such as GeoFrance [6] and the Korean Institute of Construction Technology (KICT) database. These systems allow online mapping that can accommodate the spatial complexity of geotechnical data and can maximize the sharing of data, as well as provide data analysis tools [7, 8]. However, a massive standardization of data is required in these systems. When compared to markup language systems, Geodatabase systems allow ease of adding new analysis functions and integrating tools into the system as a whole [9]. The GeoGIS does not require a standardization of data at all; all document types relevant to ALDOT's needs are included in the data entry process, allowing quick and robust data entry, storage, and retrieval.

\section{GeoGIS Data Needs}

The overarching goal of this work was to develop a userfriendly system capable of handling all subsurface data from past, present, and future transportation projects. To achieve this goal, sample project information from across Alabama was collected, analyzed, scanned, and used to develop and test a desktop prototype system. Data was collected for eight projects in seven counties and included 18 bridges that had 290 foundations and 255 soil borings. Each project was identified by a project number, and each bridge was identified by a bridge identification number (BIN). Foundations were associated with bridges while soil borings were associated with projects.

From the sample project data collected, four distinct sets of geotechnical data were identified: projects, bridges, foundations, and soil borings. Each of these geotechnical datasets has three components: (1) location, (2) attributes, and (3) scanned information. Because of the data structure and spatial component, it was determined that a GIS would provide both a framework to store geotechnical data and also a means to retrieve the data. GISs have an advantage over other database systems in that a GIS allows spatial display, querying, and selection of database information. Spatial access of data can be as simple as selecting a point or line of interest from a digital map. The four geotechnical datasets were represented as point and line features on a GIS map. The graphic entities were then associated to a limited set of keyed-in attribute data that were related to scanned information.

Because transportation projects occur at specific locations, presenting project data on a map allows information from multiple projects to be combined based solely on proximity. In addition to proximity, attribute data can associate projects. Attribute data is information that is keyed into the GIS database to describe a graphical entity on a GIS layer. Each layer in a GIS has a table that stores attribute data. Attribute tables have names and fields that store specific data about a line or point on a map. These tables can be searched for projects that meet specific criteria.

While analyzing the sample project information from across Alabama, it was determined that archived reports about site investigations, bridge construction details, and subsurface information such as foundation and soil boring data existed. The overhead to convert these reports to elemental data was far too great; therefore, the reports were scanned and stored in image or PDF format. To intuitively provide access to this information, these reports were classified into two categories: "Preconstruction" and "Construction." Preconstruction reports describe data that were generated during reconnaissance and site investigation for a project. Construction reports describe data that were generated during and after construction such as as-built plan sheets. Preconstruction data is typically related to a project, while construction data is typically related to a bridge. This information can be accessed through the project, bridge, foundation, or soil boring features on the GIS map. All single page drawing sheets, records, and reports were scanned and stored in a JPG format. Multiple-page reports were scanned 
TABLE 1: GeoGIS user types and associated privileges.

\begin{tabular}{ll}
\hline User type & Privileges \\
\hline General user & $\begin{array}{l}\text { Search, View Map, View, and Print Documents } \\
\text { Consultant }\end{array}$ \\
ALDove privileges and Upload Documents \\
Above privileges and Approve Documents, \\
Administration & $\begin{array}{l}\text { Add New Projects } \\
\text { Addition/Modification }\end{array}$ \\
\hline
\end{tabular}

and stored in PDF format so that an entire report could be accessed with one click.

\section{Web-Based GeoGIS}

Based on the success of the desktop prototype GeoGIS, a web-based system was developed. Migration of the GeoGIS from a desktop to the web allowed authorized personnel online access to the GeoGIS. An authorized GeoGIS user can access the web-based system through a login page. GeoGIS users or clients can have different privileges based on user type. All users can view maps and documents, while some users can upload and approve documents, while other users can create and manage users. The four GeoGIS user types with associated privileges are shown in Table 1.

GeoGIS is a secure website that requires a valid username and password. Once logged in, the GeoGIS homepage, shown in Figure 1, will be available with six buttons: Map, Search, Document Upload, Document Approval, Hummingbird, and Logout. Each of these buttons allows a user access to different GeoGIS functionality. These functions include viewing and searching a map, searching the database for keywords, document uploading, document approval, and a connection to the ALDOT Hummingbird database, a separate document management system.

The map function on the homepage opens a new window that displays one of three basemaps: Street, Topo, or Imagery as shown in Figure 2. Street view shows a map containing streets, street names, water bodies, and so forth; the Topo view shows USGS 7.5 minute topographic maps; the Imagery view shows aerial photography. The map page also displays the four GeoGIS layers: projects (line), bridges (stars), soil borings (yellow circles), and foundations (green circles). The map is equipped with zoom and pan functionality, and all project layers are visible and can be selected to access the associated geotechnical information.

Selecting a line or point on the map related to a project will open the associated Family Details page as shown in Figure 3. The Family Details page organized geotechnical project information into a user-friendly dynamic page that adjusts based on the information associated with a project. The page is divided into two columns: "Preconstruction" and "Construction." If a file has been uploaded to the project, the document will appear in alphabetical order below the document type and be hyperlinked to the scanned image.
All documents that have been uploaded and approved for a project can be found on the Family Details page. From the Family Details page, any document for a project can be viewed or downloaded.

A useful functionality of the GeoGIS is the thumbnail popup for files. When a user hovers over any filename, a thumbnail image of the file pops up as seen to the right of Figure 3. This is a very efficient function to quickly scan documents for the desired data. Clicking on the thumbnail will bring up the document for viewing or downloading.

To zoom directly to a project location on the map, a GeoGIS user can click the globe icon next to the project number on the Family Details page as seen in Figure 3. This automatically zooms to the project on the map and scales the map view to fit the project.

After every hyperlinked document on the Family Details page is an information page icon which takes a user to the Document Details page. The Document Details page displays data related to document upload (user and date), document approval (user and date), and attribute information such as the associated project and/or bridge. A larger and higher resolution thumbnail of the document is also available on the Document Details page.

Across the top of the Family Details page, as with any GeoGIS page, are the main GeoGIS functions that include the search function. The search page allows keyword or ID searches. The database will be searched for documents that contain the search term in the: name, project description, project reference ID, or type. The search results are displayed in a list with thumbnail views of the documents, along with the name of the document, and the Bridge Identification Number (BIN), as shown in Figure 4. This allows for quick and easy searching and selection of documents.

The Document Upload button at the top of the GeoGIS page takes a user to the Document Upload page. As shown in Table 1, the Document Upload page is only available to consultants and ALDOT engineers. The administrator can assign specific projects to consultants so that a consultant can only upload documents to assigned projects. The document upload process begins by choosing a project with a valid project ID number. The user must then select a document type and browse to the document on their computer. A bridge identification number can be entered for the document, if applicable.

Documents fall under one of two categories: preconstruction or construction documents. Types of preconstruction documents are soil surveys, geohydrologic reports, material reports, and so forth. Construction documents are bridge foundation reports, hammer submittals, drilled shaft pouring records, and so forth. A full list of the document types is shown in Table 2. Documents must be scanned or in digital format before the documents can be uploaded into the GeoGIS.

It should be noted that a project requires a line and/or points in the GIS before documents can be uploaded. The connection between the GIS and the Family Details page is made through one of two common data fields. The shapefile for a project has two attribute fields that contain the project reference ID or the family ID, which are the columns 


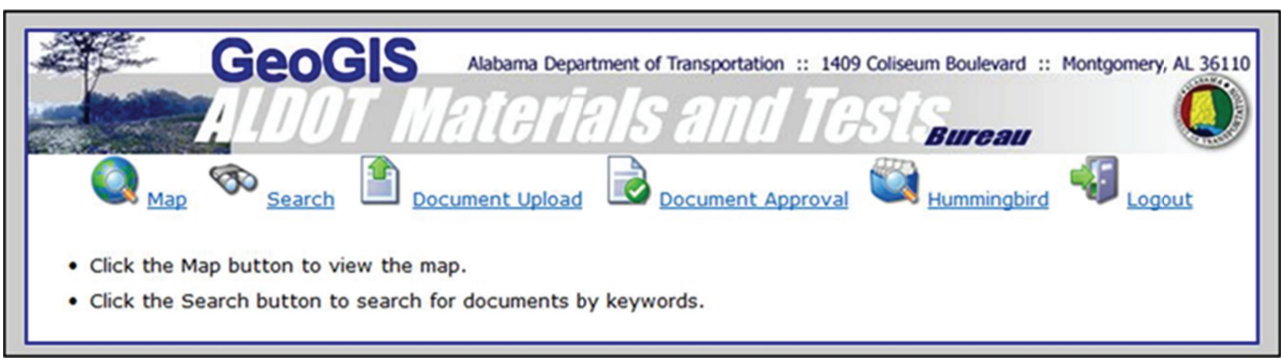

FIgURE 1: Homepage for GeoGIS.

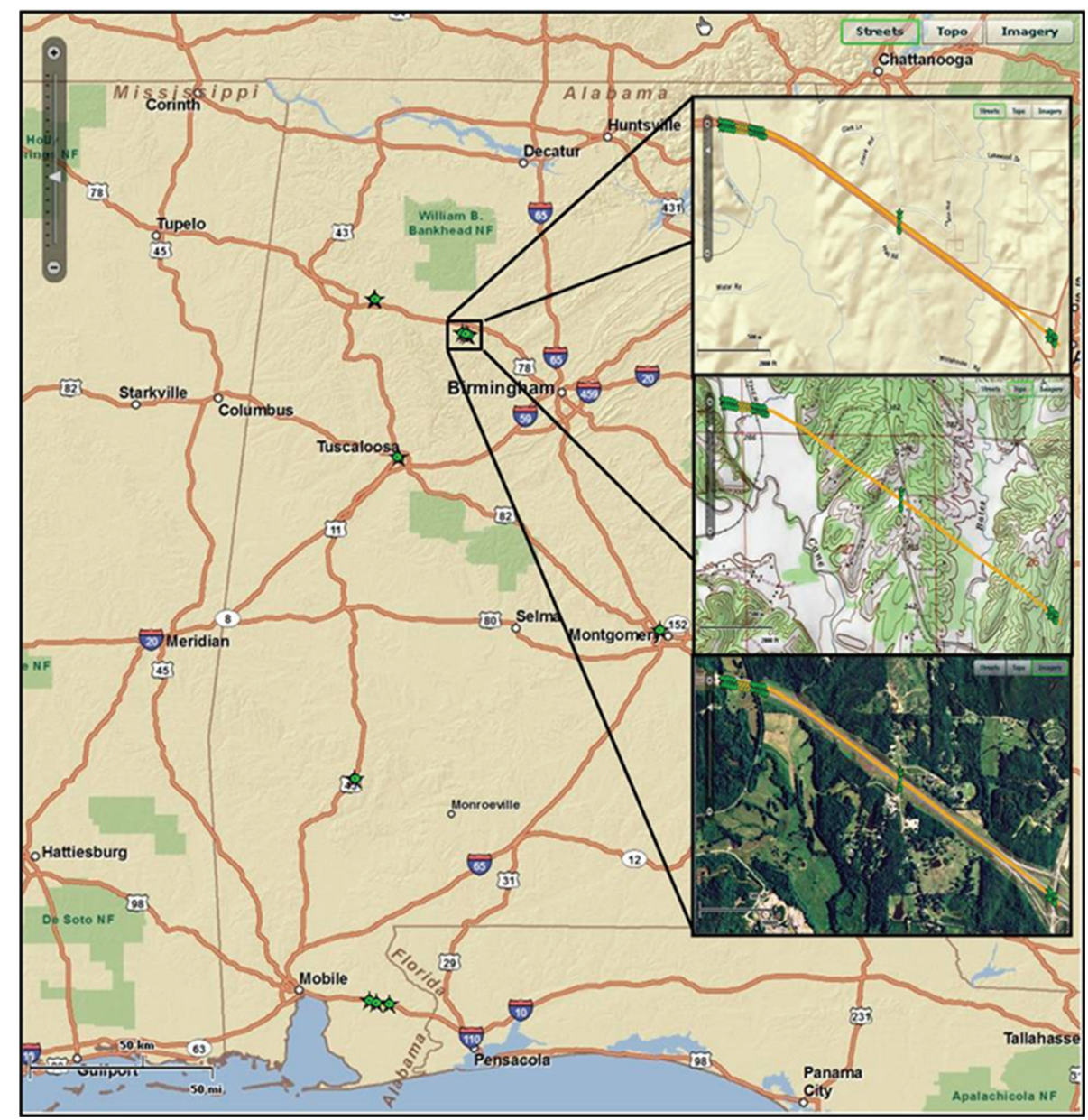

FIGURE 2: GeoGIS Map Showing Street, Topo, and Imagery Views.

the system uses to relate graphical entities on the map to the Family Details page.

Uploaded documents will not be available to GeoGIS users until the documents have been approved by a DOT engineer. The Document Approval page allows DOT engineers the ability to approve or deny documents that have been uploaded into the system. Like the Document Details page, the Document Upload page allows an engineer to view the document and details about the document. If a document is approved, the document will become searchable and viewable in the system. If a document is denied, the document will be removed from the GeoGIS database.

A link from the GeoGIS to ALDOT's general document management system is provided at the top of the GeoGIS pages through the Hummingbird button. The Hummingbird database contains all types of DOT documents including: project, management, and financial documents. Authorized users of both GeoGIS and Hummingbird can open a Hummingbird window from within the GeoGIS system by clicking the Hummingbird button. This allows access to documents beyond the scope of geotechnical data. 


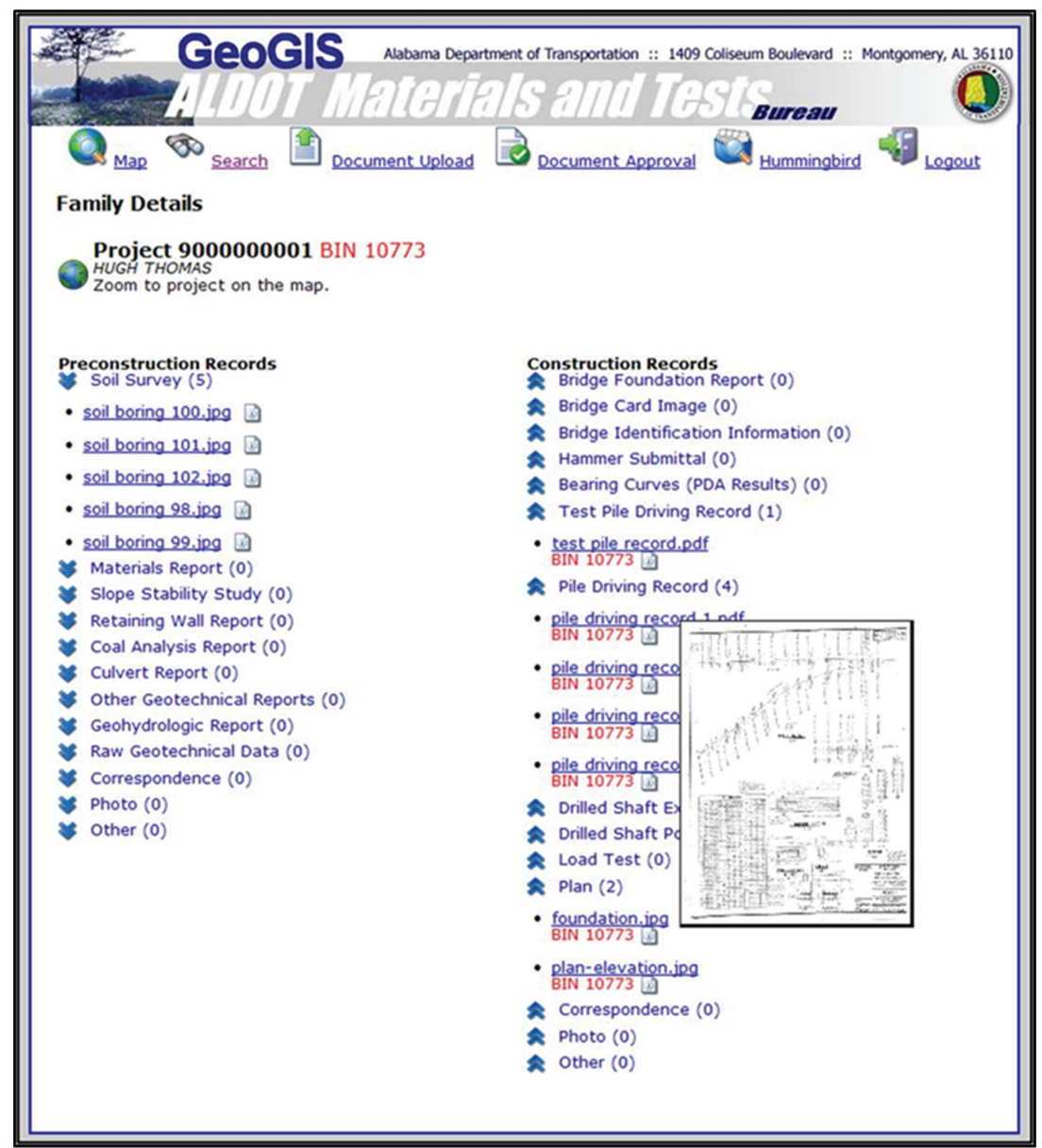

FIGURE 3: Family details page for a specific project in GeoGIS.

A GeoGIS user with administration privileges can access an Administration page. An administrator can create, delete, and modify users, passwords, and user types in the system. The Administrator also assigns consultants to specific projects for which they are allowed to upload documents. The administrator can also add new projects to the GeoGIS.

\section{Web-Based GeoGIS Architecture}

The GeoGIS website architecture, shown in Figure 5, provides flexibility and security required for this site. The GeoGIS architecture consists of a relational database, web client for document viewing and management, a map which is an extension of the web client, and an instance of ESRI's ArcGIS Server for handling map related tasks. Each of these components plays a key role in the execution of the features available in the GeoGIS web client.

The relational database is housed within a Microsoft SQL Server 2008 environment running on a host server (the computer that runs the web site client as well as the GIS program). This database stores the attribute information about projects, associated document information, information regarding web client users, and recent user activity. The web client directly interfaces with this database to display information requested by a user. This database communicates with the GIS using the project ref ID or family ID.

The GeoGIS web client is the front-end to the site and is accessed by all user types. The web client, described in detail in the previous section, web-based GeoGIS, holds a connection to the database and the map extension. By referencing projects from the database, the web client can access the map extension, via Javascript, telling the map extension to display the selected project on the map.

A Flash Map extension of the client is written with Adobe's Flex Builder. The Flash Map uses the ESRI Flex Application Programming Interface (API) for interfacing with ArcGIS Server (another ESRI application), allowing rich and dynamic web applications to be created. This map communicates with the ArcGIS instance, allowing the map to "pull down" the necessary information to display projects on a map.

ESRI ArcGIS server resides on a host machine and serves up the location data and map tiles needed for the map extension to display projects. ESRI is a partnering GIS 




Figure 4: Search page in GeoGIS.

company that offers the interface that provides a rich user experience for projects involving maps.

\section{Conclusions and Future Work}

A web-based system entitled GeoGIS was developed to efficiently upload, store, and retrieve geotechnical data associated with projects and bridges in the state of Alabama. This secure website can be accessed by DOT employees as well as other authorized users from outside consulting firms. The system focuses on geotechnical documentation that is spatially located. A limited amount of attribute data is employed to facilitate keyword searches. The GeoGIS is designed to be expanded to accommodate all types of geotechnical data for the state of Alabama and is not restricted to scanned documents. Future upgrades to the system will include complex spatial querying capabilities, a tighter integration of the map and SQL database, and tighter integration with the existing Hummingbird document management system at ALDOT. 


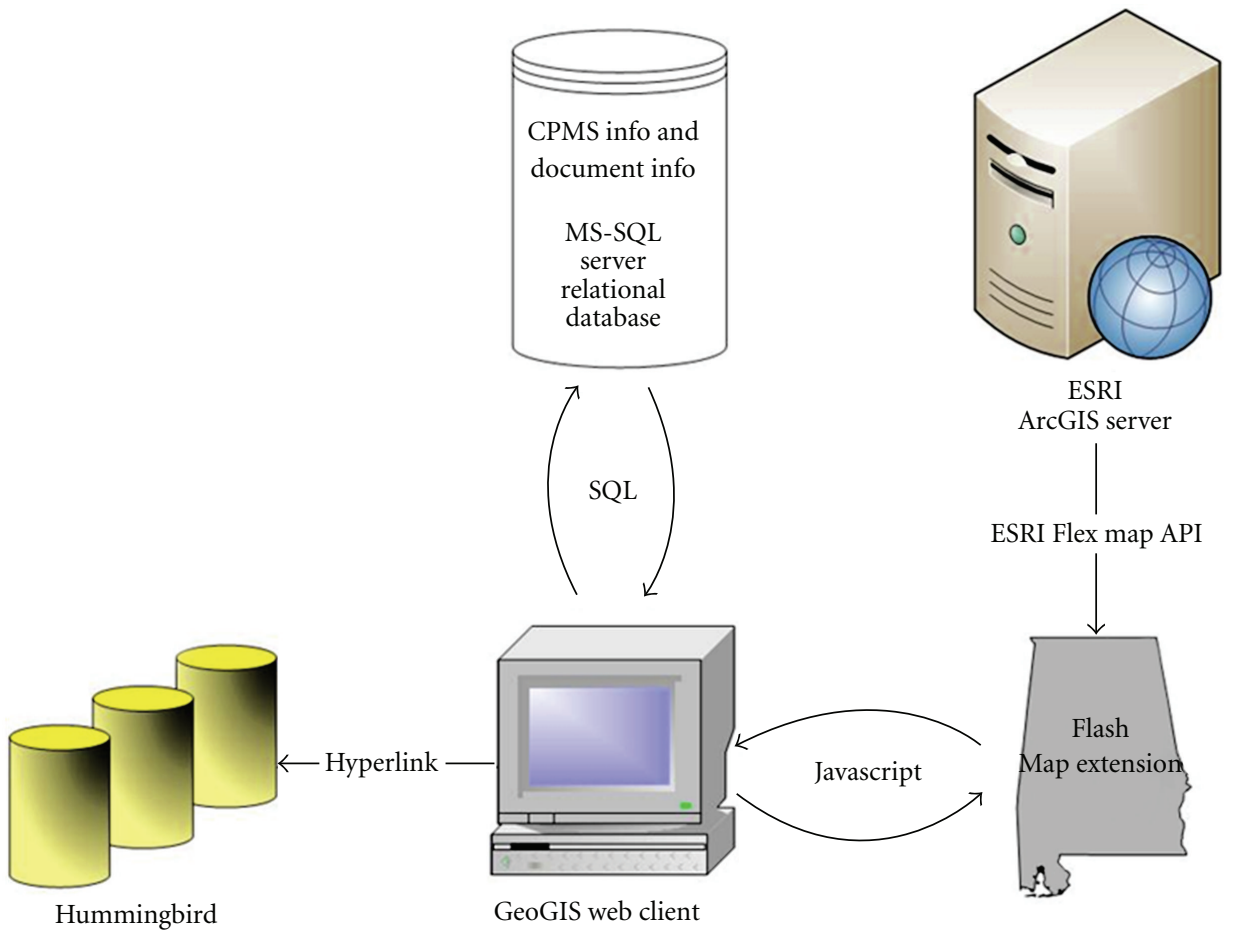

FIGURE 5: GeoGIS architecture flowchart.

TABle 2: Preconstruction and construction document types.

\begin{tabular}{ll}
\hline Preconstruction & Construction \\
\hline Soil survey & Bridge card image \\
Materials report & Bridge identification \\
Bridge foundation report & Hammer submittal \\
Slope stability study & Bearing curves (PDA results) \\
Retaining wall report & Test pile driving record \\
Coal analysis report & Pile driving record \\
Culvert report & Drilled shaft excavation log \\
Other geotechnical reports & Drilled shaft pouring record \\
Geohydrologic report & Load test \\
Raw geotechnical data & Plan \\
Correspondence & Correspondence \\
Photo & Photo \\
Other & Other \\
\hline
\end{tabular}

\section{Acknowledgments}

The authors would like to acknowledge the Alabama Department of Transportation for supporting this work. In addition, the authors would like to acknowledge the programming support provided by John Pappas and Justin McDaniel, as well as the Center for Advanced Public Safety at The University of Alabama.

\section{References}

[1] T. E. Lefchik and K. Beach, "Development of national geotechnical management system standards for transportation applications," in Proceedings of the Geotechnical Engineering in the Information Technology Age (GeoCongress '06), p. 108, American Society of Civil Engineers ( ASCE ), Atlanta, Ga, USA, March 2006.

[2] D. G. Toll and A. C. Cubitt, "Representing geotechnical entities on the world wide web," Advances in Engineering Software, vol. 34, no. 11-12, pp. 729-736, 2003.

[3] A. Turichshev, Web-accessible relational database for intact rock properties and an XML data format for intact rock properties, M.S. thesis, Arts and Sciences, University of Toronto, 2002.

[4] M. Sen and T. Duffy, "GeoSciML: development of a generic geoscience markup language," Computers \& Geosciences, vol. 31, no. 9, pp. 1095-1103, 2005.

[5] J. Kunapo, G. R. Dasari, K. K. Phoon, and T. S. Tan, "Development of a Web-GIS based geotechnical information system," Journal of Computing in Civil Engineering, vol. 19, no. 3, pp. 323-327, 2005.

[6] A. Guillen, C. Meunier, X. Renaud, and P. Repusseau, "New internet tools to manage geological and geophysical data," Computers \& Geosciences, vol. 27, no. 5, pp. 563-575, 2001.

[7] Y. S. Chang and H. D. Park, "Development of a webbased geographic information system for the management of borehole and geological data," Computers \& Geosciences, vol. 30, no. 8, pp. 887-897, 2004.

[8] C. Y. L. Cintron, Development of a geotechnical database for the city of Mayaguez, Puerto Rico, M.S. thesis, Civil Engineering, University of Puerto Rico, Mayaguez Campus, 2007.

[9] J.-W. Chung, Development of a geographic information systembased virtual geotechnical database and assessment of liquefaction potential for the St. Louis Metropolitan area, Ph.D. dissertation, Geological Engineering, University of Missouri-Rolla, 2007. 

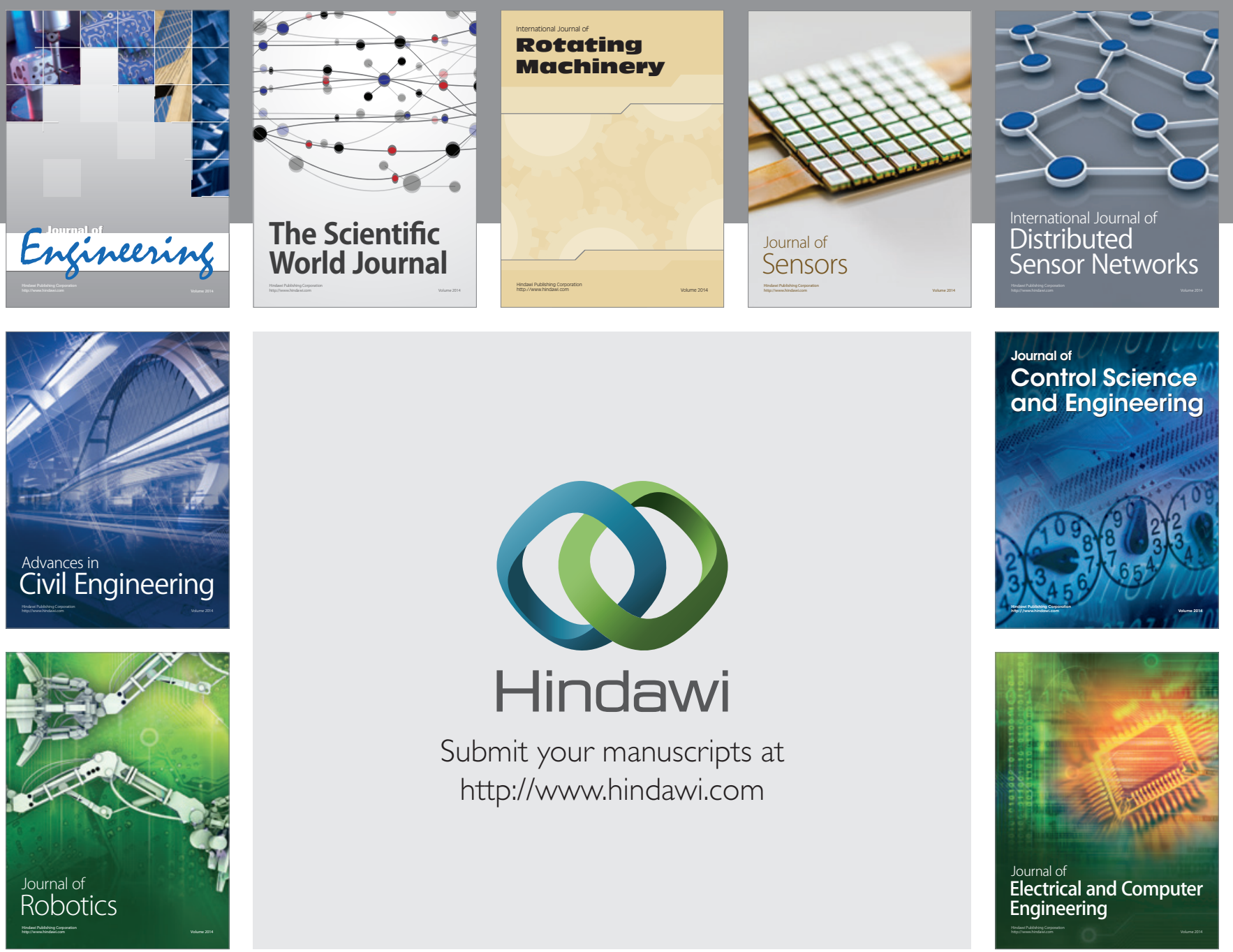

Submit your manuscripts at

http://www.hindawi.com
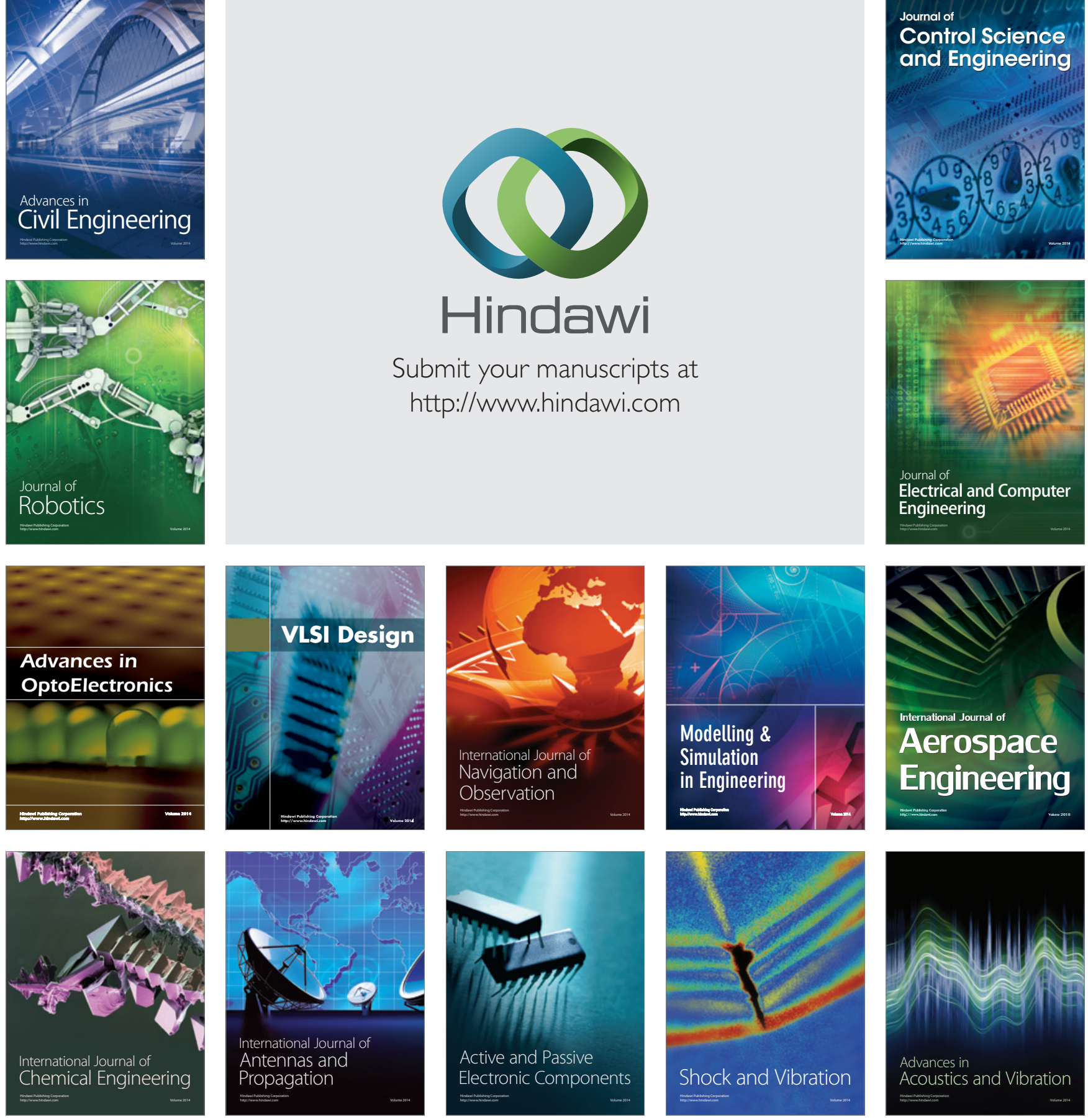